\title{
New topical treatment of vulvodynia based on the pathogenetic role of cross talk between nociceptors, immunocompetent cells, and epithelial cells
}

\author{
This article was published in the following Dove Press journal: \\ Journal of Pain Research \\ 3 October 2016 \\ Number of times this article has been viewed
}

\section{J M Keppel Hesselink' \\ D J Kopsky² \\ $N$ Sajben ${ }^{3}$}

'Institute for Neuropathic Pain, Bosch en Duin, ${ }^{2}$ Institute for Neuropathic Pain, Amsterdam, The Netherlands; ${ }^{3}$ Scripps Memorial Hospital La Jolla, La Jolla, CA, USA

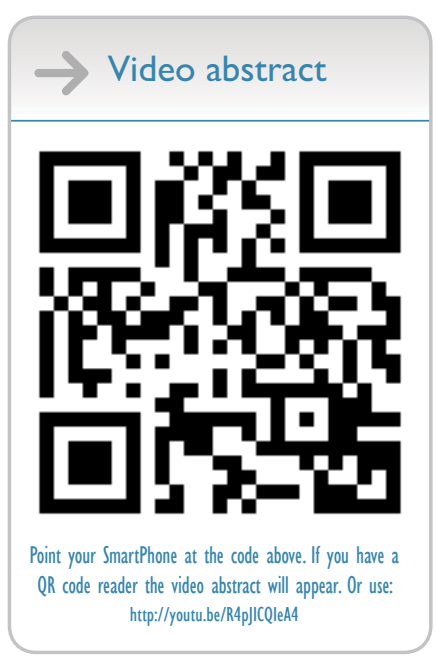

Correspondence: J M Keppel Hesselink Institute for Neuropathic Pain, Spoorlaan 37a, 3735 MV, Bosch en Duin,

The Netherlands

Tel +3I 65I700527

Email jan@neuropathie.nu

\begin{abstract}
Topical treatments of localized neuropathic pain syndromes in general are mostly neglected, mainly due to the fact that most pain physicians expect that a topical formulation needs to result in a transdermal delivery of the active compounds. On the basis of the practical experience, this study brings forth a new, somewhat neglected element of the vulvodynia pathogenesis: the cross talk between the nerve endings of nociceptors, the adjacent immunocompetent cells, and vaginal epithelial cells. Insight into this cross talk during a pathogenic condition supports the treatment of vulvodynia with topical (compounded) creams. Vulvodynia was successfully treated with an analgesic cream consisting of baclofen $5 \%$ together with the autacoid palmitoylethanolamide $1 \%$, an endogenous anti-inflammatory compound. In this review, data is presented to substantiate the rationale behind developing and prescribing topical products for localized pain states such as vulvodynia. Most chronic inflammatory disorders are based on a network pathogenesis, and monotherapeutic inroads into the treatment of such disorders are obsolete.

Keywords: vulva, cream, autacoid, mast cell, pain, analgesia, pathogenesis, baclofen, palmitoylethanolamide
\end{abstract}

\section{Introduction}

Vulvodynia is frequently present in women between 18 and 60 years, with a prevalence between $4 \%$ and $16 \%$, though it may be underestimated due to underreporting bias. Although the International Society for the Study of Vulvovaginal Disease defines vulvodynia as "vulvar pain occurring in the absence of an underlying recognizable disease", we think its pathogenesis can be defined within certain boundaries in such a way that rational therapy can emerge. ${ }^{1}$

Vulvodynia is differentiated into localized and generalized subtypes, although both these are probably extreme variations of one syndrome. ${ }^{1}$ Localized provoked vestibulodynia or vulvodynia (LPV) is a clinical diagnosis and is defined by a characteristic pattern of mechanical allodynia localized to the vulvar vestibule upon stimulation. ${ }^{2}$ However, the classification of this disorder is still very much in flux. In 2015, new nomenclature was developed at a vulvar pain and vulvodynia consensus conference supported by International Society for the Study of Vulvovaginal Disease, the International Society for the Study of Women's Sexual Health, and the International Pelvic Pain Society, and this needs further consolidation.

Most LPV cases can be regarded as a manifestation of a (localized) neuropathic pain disorder because vulvodynia is described by patients as burning, stinging, irritation, 
and/or rawness, and thus has comparable pain characteristics as postherpetic neuralgia and complex regional pain syndrome. ${ }^{3}$ In this article, we will not differentiate between the local and the generalized variety of vulvodynia, and we will use the term vulvodynia to cover all primary and secondary or generalized varieties.

The therapy of vulvodynia is still in its infancy, and many treatment options have been extrapolated from other fields, such neuropathic pain or infectious disease. Furthermore, most treatment recommendations are based on personal opinions and are based neither on an extensive understanding of the pathogenesis of this disorder nor on the results of robust methodologically sound clinical trials. One of the key players in the pathogenesis not generally recognized might be the epithelial cell, a cell in close contact with nerve endings of nociceptors in the vaginal area in such a way that cross talk occurs between these components and other components such as immune competent cells (eg, mast cells).

A new putative treatment option for vulvodynia will be discussed based on the application of topical analgesia alone or in combination with autacoids, such as palmitoylethanolamide, the latter administered either locally or systemically. We feel that new therapeutic options based on the combination of specifically selected active compounds influencing the pathogenetic cross talk between epithelial cells, upregulated vulvar nociceptors, as well as the immunocompetent cells in this area, should be taken into consideration.

On the basis of our past experience in prescribing topical analgesic creams containing baclofen or amitriptyline, together with the autacoid palmitoylethanolamide, to women suffering from vulvodynia, we have identified some important facts. The latter compound (palmitoylethanolamide) was sometimes not only coadministered in the analgesic cream, but also given as $400 \mathrm{mg}$ capsules orally three times daily. We have previously published an exemplary case report on this effective combination. ${ }^{4}$

In our experience, baclofen is a more optimal compound than amitriptyline, first because in addition to its topical analgesic effect it most probably may relax the pudendal muscles and second because topical amitriptyline can sometimes cause burning sensation as a side effect.

\section{Pathogenesis of vulvodynia}

In this article, we will point out a new treatment modality for vulvodynia, based on what we see as key elements of its pathogenesis: the cross talk between nerve endings of nociceptors, adjacent immunocompetent cells, and epithelial cells. We will discuss these three components separately hereunder, although the upregulated nociceptors resulting in neuropathic pain and the immunocompetent component resulting in (neuro)inflammation are difficult to separate. As the epithelial component is generally overlooked, we will give some extra attention to this component. However, while there are many mechanistic models to study neuropathic pain, models for vulvar pain are extremely rare. ${ }^{5}$ This is partly due to the fact that the vaginal epithelial tissue in rats and other laboratory animals is quite different from human vaginal epithelium. The lining epithelium of the vagina is stratified squamous, comparable to keratinocytes. It has been quite difficult to differentiate between skin, buccal, and vaginal epithelial cells as there are many similarities. ${ }^{6}$ As there is nonexistent literature on the role of epithelial cells in vulvodynia, we need to extrapolate from recent findings of the biology of dermal epithelial cells (keratinocytes) as well as from neuropathic pain research.

\section{Neuropathic pain component}

As evidence for the underlying etiology of vulvodynia remains elusive, insight in the pathogenesis can bear more weight for determining its therapy. Neuropathic pain is claimed by some authors to be the most relevant explanation of vulvodynia, much more than infections with Candida or Epstein-Barr virus. ${ }^{3}$ In 1998, an increase in the density of nerve endings was described in the vestibular tissues of women with LPV who had undergone vulvar vestibulectomy compared with controls. ${ }^{7,8}$ These nerve endings were later characterized as nociceptors. ${ }^{9}$ These findings have since been duplicated multiple times. ${ }^{10,11}$ Genitofemoral neuralgia, a clear neuropathic pain condition, and local entrapment syndromes, described in patients suffering from vulvodynia, are all supportive evidence for a neuropathic pain component in vulvodynia. ${ }^{12,13}$

\section{(Neuro)inflammatory component}

In patients suffering from vulvodynia, increased concentration of mast cells has been found in vulvar biopsies. ${ }^{14}$ However, more recently, such findings have not been duplicated. ${ }^{15}$ We need to understand that mast cell density, determined as "the average number of mast cells per $400 \times$ magnification field", might not be a relevant parameter in itself at all. A more functional parameter may play a role: mast cell reactivity. ${ }^{16}$ An exaggerated response to inflammation due to decreased ability to downregulate the inflammatory activity is currently seen as a cornerstone in disease pathogenesis. ${ }^{3}$ Vulvodynia has been recognized as a cytokine-mediated pain syndrome, characterized by increases in proinflammatory cytokines, such as IL-8, and decreases in anti-inflammatory cytokines, such as IL-10. ${ }^{17}$ Blood samples from patients 
with vestibulodynia have shown enhanced induction of a proinflammatory cytokine (IL-1 $\beta$ ) and decreased production of anti-inflammatory mediator (IL-1 receptor antagonist) as compared with controls. ${ }^{18}$ Neuroinflammation has been extensively discussed recently as a pathogenetic component in vulvodynia, and it was pointed out that localized neuroinflammatory processes may alter the ion channel activity of peripheral axons and subsequently lower the mechanical and thermal thresholds in primary vulvar afferents, resulting in sensitization and enhanced perception of pain in the affected area. ${ }^{19}$ These derangements can subsequently lead to peripheral and central wind-up and sensitization. ${ }^{20}$ Abnormal inflammatory response and heightened sensitivity, hyperinnervation, neuroinflammation, sensory abnormalities, lowered pain threshold for several mechanical, chemical, and thermal stimuli, and tissue alterations and development of central nervous system sensitization are mentioned as key pathological findings in vulvodynia. ${ }^{2,19,21-23}$

Within the context of (neuro)inflammation, we suggest that it would be very likely that in vulvodynia the synthesis of the autacoid bioactive lipids from the classes $\mathrm{N}$-acylethanolamides (among which palmitoylethanolamide), lipoxins, maresins, resolvins, and protectins is disturbed. All these autacoids are proresolving and anti-inflammatory lipids that help to inhibit overactive inflammatory processes and have, for some years, been the focus of attention for the treatment of a number of inflammatory disorders. ${ }^{24}$ However, apparently no reference has been made to these important compounds for the treatment of vulvodynia.

\section{Epithelial component}

For the past 50 years, it has become clear that epithelial cells such as the keratinocytes are not solely programmed for a protective and lining role. This cell has more biological functions. Active phagocytosis is one of the first immune-related functions described in the 1960s and 1970s. ${ }^{25,26}$ Keratinocytes and other epithelial cells are in close functional contact with sensory afferent nerves (eg, nociceptors) and immunocompetent cells (eg, mast cells). Stimulation of keratinocytes alone is already sufficient to induce expression of the neuronal activation marker, c-fos, in the spinal cord dorsal horn and evokes pain behavior. ${ }^{27}$ The epithelial cells also express a number of neuropeptides and neurotransmitters known to be involved in localized inflammatory processes. ${ }^{28}$ The keratinocyte is programmed to release a number of neuro- and immune-activating molecules, such as calcitonin gene-related peptide, adenosine triphosphate, acetylcholine, glutamate, various growth factors, cytokines, and possibly many other autacoids, in response to noxious stimuli. ${ }^{29}$ As nociceptors terminate in the periphery as free nerve endings, they can be directly in contact with injured tissue, and therefore any cell of the vaginal mucosa can serve as a potential sensory receptor of injury. ${ }^{30}$ The close apposition of keratinocytes with such sensory afferents was first described in $1995 .{ }^{31}$ These epithelial cells also carry many neuronal- and immunerelated receptors, all of which are suspected to play different roles in peripheral upregulation and in chronification of pain. ${ }^{32}$ These are some of the receptors that play a role: $\alpha 1$-adrenoceptors, many voltage-gated sodium channels, the temperature-sensitive transient receptor potential ion channels (thermoTRPs), substance P, neurokinin A, endothelin receptors, Toll-like receptors, and interleukin receptors, such as IL-1 $\beta$ and IL-31 receptors. All this supports and explains the putative role of topical analgesic creams in treating chronic pain, concluding that "Vaginal Epithelia Matters!" 33

Platform of cross talk of nociceptors, immunocompetent cells, and epithelial cells and NGF as an example in the pathogenetic network.

Many of us are accustomed to studying tissues from the perspective of histology, as two-dimensional static pictures, which only shows cells make contact with each other by approximation. ${ }^{34}$ This has wired our thinking about cells and tissues and their interaction in a certain mode, which is neither fluid nor in tune with four-dimensional aspects. A four-dimensional view is necessary because there is a network of interactions unfolding with time in each tissue and between the cells in a tissue. For some years, new biological findings demonstrate how refined and complex this network can be. Many hundreds of cells and molecules, such as neurotransmitters and autacoids, play a role and create an utterly dynamic picture. We will only point out some of these interactions and focus as an example on only one molecule, neurotrophic growth factor (NGF), which supports our understanding of the dimensions of the new hypothesis we herein put forward. It is this single molecule, NGF, which is involved in cross talk between the intimately related epithelial tissue, immunocompetent cells, and neuronal components.

NGF is thus recognized as one biological factor influencing each of the three components: epithelial cells, immunocompetent cells, and nociceptors (Figure 1). NGF is a major biological actor that was first identified in pain and inflammation by the Nobel laureate Rita Levi-Montalcini in the last century. ${ }^{35,36} \mathrm{NGF}$ is the most commonly studied growth factor in relation to nociceptor sensitization and mast cell activation. ${ }^{37-39}$ 


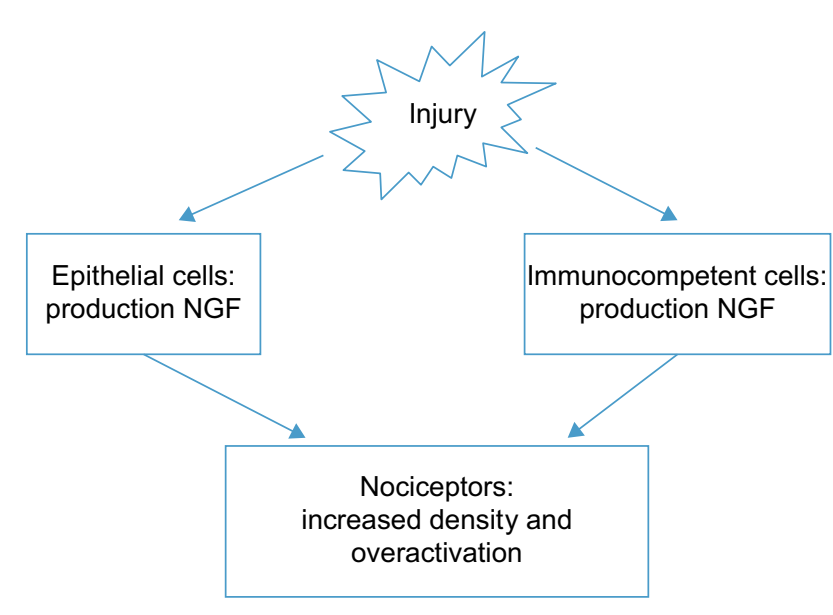

Figure I NGF production.

Abbreviation: NGF, neurotrophic growth factor.

Levi-Montalcini was also the first to hypothesize that one compound could inhibit the positive feedback loop of overactive mast cells producing NGF: the autacoid palmitoylethanolamide. This is a compound of our topical creams. ${ }^{38,40-45}$

NGF also has intimate relations with keratinocytes; for instance, in a neuropathic pain model, NGF immunoreactivity was increased in mast cells as well as in keratinocytes. ${ }^{46} \mathrm{Also}$, keratinocytes can become NGF-producing cells in inflammatory models, together with other proinflammatory cytokines, thus augmenting neuropeptide signaling by substance $P$ and calcitonin gene-related peptide. ${ }^{47}$

Therefore, apart from the mast cell-positive feedback loop described by Levi-Montalcini, NGF can act upon and can be produced by various other cells, such as the neutrophils and the keratinocytes, that then release additional inflammatory mediators causing hypersensitivity ${ }^{48}$ NGF induces sprouting and upregulates innervation density of NGF-responsive neurons in peripheral targets. ${ }^{49}$

Mast cells also produce prostaglandin E2, an enhancer of neurogenesis. This metabolite can activate the TRPV1 receptor, and NGF can subsequently promote the insertion of TRPV1 into the cell surface membrane. ${ }^{50}$

In a model of chronic prostatitis related to vulvodynia, mast cell tryptase and NGF were upregulated and correlated with reduced thresholds to probing (noxic stimulation) of the abdomen as well as with the upregulation of nociceptive markers in nerves innervating the prostate tissues. ${ }^{51}$

Like NGF, other biologically active molecules also probably play a comparable complex role in this cross talk. For instance, during inflammatory responses, skin keratinocytes generate the antimicrobial peptide LL-37, and this molecule again induces functional changes in mast cells related to our innate immunity. ${ }^{52}$
The aforementioned biological findings demonstrate an upregulation of three main components: nociceptors, immunocompetent cells, and epithelial cells. Each component influences the others via a multitude of mechanisms of action. NGF is just one example of a biological factor influencing all these components and is used to demonstrate this intimate cross talk.

\section{Rationale for topical treatment with baclofen-palmitoylethanolamide}

On the basis of the previously mentioned points, topical treatment of vulvodynia may bring relief from pain by targeting local components of the vaginal epithelium, such as free nerve endings of nociceptors, immunocompetent cells, and epithelial cells. Topical treatments can be used either as monotherapy or as an element of polypharmacy. We prescribed compounded creams containing both analgesic and anti-inflammatory compounds, such as baclofen $5 \%$ and palmitoylethanolamide $1 \%$, for the treatment of LPV. Insight into the therapeutic role of autacoids in restoring neuroinmmunological homeostasis is an exciting new field, and such autacoids as palmitoylethanolamide can be added to analgesic creams. Other compounds from the autacoid classes of lipoxins, maresins, protectins, and resolvins are also candidates.

It is clear that physicochemical properties of compounds in analgesic creams will have to be taken into consideration while developing such treatments. We have experimented with a variety of creams and developed one specific base, which is able to contain both lipophilic and hydrophilic compounds without pharmaceutical complications, resulting in stable creams with a shelf life of 2 years. By prescribing these compounded analgesic creams containing, for instance, baclofen and palmitoylethanolamide, it is possible to reduce vulvodynia, possibly achieving synergistic effects with active pharmaceutical compounds and the body's own autacoids. ${ }^{4,41-45}$

\section{Conclusion}

A new treatment modality was proposed for vulvodynia, which is based on the cross talk between the three components: nerve endings of nociceptors, adjacent immunocompetent cells, and epithelial cells. There is a wealth of data supporting an intimate relationship between these three components, pointing out that the many factors emerging from this interplay all lead to peripheral and central wind-up and sensitization. The topical treatment of vulvodynia that we currently propose and explore may bring relief of pain due to 
targeting the three components. Such topical treatments can be used either as monotherapy or as part of polypharmacy, the latter is more preferable given the multicausal characteristics of the pathogenetic cross talk. We use compounded creams containing both analgesic and anti-inflammatory compounds, such as baclofen $5 \%$ and palmitoylethanolamide $1 \%$. Such a cream might be effective as it restores the neuroimmunological homeostasis in the vaginal tissue due to the action of the autacoid palmitoylethanolamide. This is an exciting new field, and the autacoid palmitoylethanolamide or other compounds from the comparable classes such as lipoxins, maresins, protectins, and resolvins could be candidates for a multifactorial analgesic cream.

\section{Disclosure}

The authors report no conflicts of interests in this work.

\section{References}

1. Moyal-Barracco M, Lynch PJ. 2003 ISSVD terminology and classification of vulvodynia: a historical perspective. J Reprod Med. 2004;49(10):772-777.

2. Wesselmann U, Bonham A, Foster D. Vulvodynia: current state of the biological science. Pain. 2014;155(9):1696-1701.

3. Eppsteiner E, Boardman L, Stockdale CK. Vulvodynia. Best Pract Res Clin Obstet Gynaecol. 2014;28(7):1000-1012.

4. Keppel Hesselink JM, Kopsky DJ, Sajben NL. Vulvodynia and proctodynia treated with topical baclofen 5\% and palmitoylethanolamide. Arch Gynecol Obstet. 2014;290(2):389-393.

5. Martinov T, Glenn-Finer R, Burley S, et al. Contact hypersensitivity to oxazolone provokes vulvar mechanical hyperalgesia in mice. PLoS One. 2013;8(10):e78673.

6. French CE, Jensen CG, Vintiner SK, Elliot DA, McGlashan SR. A novel histological technique for distinguishing between epithelial cells in forensic casework. Forensic Sci Int. 2008;178(1):1-6.

7. Westrom LV, Willen R. Vestibular nerve fiber proliferation in vulvar vestibulitis syndrome. Obstet Gynecol. 1998;91(4):572-576.

8. Bohm-Starke N, Hilliges M, Falconer C, Rylander E. Increased intraepithelial innervation in women with vulvar vestibulitis syndrome. Gynecol Obstet Invest. 1998;46(4):256-260.

9. Bohm-Starke N, Hilliges M, Falconer C, Rylander E. Neurochemical characterization of the vestibular nerves in women with vulvar vestibulitis syndrome. Gynecol Obstet Invest. 1999;48(4):270-275.

10. Leclair CM, Goetsch MF, Korcheva VB, Anderson R, Peters D, Morgan TK. Differences in primary compared with secondary vestibulodynia by immunohistochemistry. Obstet Gynecol. 2011;117(6):1307-1313.

11. Goetsch MF, Morgan TK, Korcheva VB, Li H, Peters D, Leclair $\mathrm{CM}$. Histologic and receptor analysis of primary and secondary vestibulodynia and controls: a prospective study. Am J Obstet Gynecol. 2010;202(6):28.

12. Verstraelen H, De Zutter E, De Muynck M. Genitofemoral neuralgia: adding to the burden of chronic vulvar pain. J Pain Res. 2015;8: 845-849.

13. Possover M, Forman A. Pelvic neuralgias by neuro-vascular entrapment: anatomical findings in a series of 97 consecutive patients treated by laparoscopic nerve decompression. Pain Physician. 2015;18(6):E1139-E1143.

14. Goetsch MF, Morgan TK, Korcheva VB, Li H, Peters D, Leclair CM. Histologic and receptor analysis of primary and secondary vestibulodynia and controls: a prospective study. Am JObstet Gynecol. 2010;202(6):614 e1-e8.
15. Papoutsis D, Haefner HK, Crum CP, Opipari AW Jr, Reed BD. Vestibular mast cell density in vulvodynia: a case-controlled study. J Low Genit Tract Dis. 2016;20(3):275-279.

16. Pearce FL, Frenz AM, Shah PM. Changes in mast cell reactivity in the course of allergic inflammation. Inflamm Res. 1996;45 (Suppl 1):S31-S32.

17. Baker DA, Peresleni T, Kocis C. Inflammatory markers in vestibulodynia [4]. Obstet Gynecol. 2016;127 (Suppl 1):1S-2S.

18. Gerber S, Bongiovanni AM, Ledger WJ, Witkin SS. Defective regulation of the proinflammatory immune response in women with vulvar vestibulitis syndrome. Am J Obstet Gynecol. 2002;186(4):696-700.

19. Akopians AL, Rapkin AJ. Vulvodynia: the role of inflammation in the etiology of localized provoked pain of the vulvar vestibule (vestibulodynia). Semin Reprod Med. 2015;33(4):239-245.

20. Yunus MB. Editorial review: an update on central sensitivity syndromes and the issues of nosology and psychobiology. Curr Rheumatol Rev. 2015;11(2):70-85.

21. Bohm-Starke N, Falconer C, Rylander E, Hilliges M. The expression of cyclooxygenase 2 and inducible nitric oxide synthase indicates no active inflammation in vulvar vestibulitis. Acta Obstet Gynecol Scand. 2001;80(7):638-644.

22. Pukall CF, Binik YM, Khalife S, Amsel R, Abbott FV. Vestibular tactile and pain thresholds in women with vulvar vestibulitis syndrome. Pain. 2002;96(1-2):163-175.

23. Sonni L, Cattaneo A, De Marco A, De Magnis A, Carli P, Marabini S. Idiopathic vulvodynia. Clinical evaluation of the pain threshold with acetic acid solutions. J Reprod Med. 1995;40(5):337-341.

24. Weylandt KH. Docosapentaenoic acid derived metabolites and mediators - the new world of lipid mediator medicine in a nutshell. Eur $J$ Pharmacol. 2016;785:108-115.

25. Wolff K, Schreiner E. Uptake, intracellular transport and degradation of exogenous protein by langerhans cells. An electron-microscopiccytochemical study using peroxidase as tracer substance. $J$ Invest Dermatol. 1970;54:(1):37-47.

26. Wolff K, Konrad K. Phagocytosis of latex beads by epidermal keratinocytes in vivo. J Ultrastruct Res. 1972;39(3):262-280.

27. Pang Z, Sakamoto T, Tiwari V, et al. Selective keratinocyte stimulation is sufficient to evoke nociception in mice. Pain. 2015;156(4):656-665.

28. Sloniecka M, Le Roux S, Boman P, Bystrom B, Zhou Q, Danielson P. Expression profiles of neuropeptides, neurotransmitters, and their receptors in human keratocytes in vitro and in situ. PLoS One. 2015; 10(7): $\mathrm{e} 0134157$.

29. Ritter-Jones M, Najjar S, Albers KM. Keratinocytes as modulators of sensory afferent firing. Pain. 2016;157(4):786-787.

30. Cook SP, McCleskey EW. Cell damage excites nociceptors through release of cytosolic ATP. Pain. 2002;95(1-2):41-47.

31. Hilliges M, Wang L, Johansson O. Ultrastructural evidence for nerve fibers within all vital layers of the human epidermis. J Invest Dermatol. 1995;104(1):134-137.

32. Sikandar S, Aasvang EK, Dickenson AH. Scratching the surface: the processing of pain from deep tissues. Pain Manag. 2016;6(2):95-102.

33. Shipton EA. Skin matters: identifying pain mechanisms and predicting treatment outcomes. Neurol Res Int. 2013;2013:329364.

34. Mione S, Valcke M, Cornelissen M. Remote histology learning from static versus dynamic microscopic images. Anat Sci Educ. 2016;9(3):222-230.

35. Aloe L, Chaldakov GN. The multiple life of nerve growth factor: tribute to rita levi-montalcini (1909-2012). Balkan Med J. 2013;30(1):4-7.

36. Levi-Montalcini R, Dal Toso R, della Valle F, Skaper SD, Leon A. Update of the NGF saga. J Neurol Sci. 1995;130(2):119-127.

37. Aloe $\mathrm{L}$. The effect of nerve growth factor and its antibody on mast cells in vivo. J Neuroimmunol. 1988;18(1):1-12.

38. Kritas SK, Caraffa A, Antinolfi P, et al. Nerve growth factor interactions with mast cells. Int J Immunopathol Pharmacol. 2014;27(1):15-19.

39. Levi-Montalcini R, Skaper SD, Dal Toso R, Petrelli L, Leon A. Nerve growth factor: from neurotrophin to neurokine. Trends Neurosci. 1996;19(11):514-520. 
40. Keppel Hesselink JM. Professor Rita Levi-Montalcini on nerve growth factor, mast cells and palmitoylethanolamide, an endogenous antiinflammatory and analgesic compound. J Pain Relief. 2013;2:114.

41. Kopsky DJ, Keppel Hesselink JM. A new combination cream for the treatment of severe neuropathic pain. J Pain Symptom Manage. 2010;39(2):e9-e10.

42. Kopsky DJ, Keppel Hesselink JM. Multimodal stepped care approach involving topical analgesics for severe intractable neuropathic pain in CRPS type 1: a case report. Case Rep Med. 2011;2011:319750.

43. Kopsky DJ, Keppel Hesselink JM. Neuropathic pain as a result of acromegaly, treated with topical baclofen cream. J Pain Symptom Manage. 2013;46(4):e4-e5.

44. Kopsky DJ, Hesselink JM. High doses of topical amitriptyline in neuropathic pain: two cases and literature review. Pain Pract. 2012;12(2):148-153.

45. Liebregts R, Kopsky DJ, Hesselink JM. Topical amitriptyline in posttraumatic neuropathic pain. J Pain Symptom Manage. 2011;41(4):e6-e7.

46. Peleshok JC, Ribeiro-da-Silva A. Neurotrophic factor changes in the rat thick skin following chronic constriction injury of the sciatic nerve. Mol Pain. 2012;8:1.
47. Shi X, Wang L, Clark JD, Kingery WS. Keratinocytes express cytokines and nerve growth factor in response to neuropeptide activation of the ERK1/2 and JNK MAPK transcription pathways. Regul Pept. 2013;186:92-103.

48. Kritas SK, Saggini A, Cerulli G, et al. Neuropeptide NGF mediates neuro-immune response and inflammation through mast cell activation. J Biol Regul Homeost Agents. 2014;28(2):177-181.

49. Jankowski MP, Koerber HR. Neurotrophic factors and nociceptor sensitization. In: Kruger L, Light AR, editors. Translational Pain Research: From Mouse to Man. CRC Press: Boca Raton, FL; 2010.

50. Shibata T, Takahashi K, Matsubara Y, et al. Identification of a prostaglandin D2 metabolite as a neuritogenesis enhancer targeting the TRPV1 ion channel. Sci Rep. 2016;6:21261.

51. Schwartz ES, Xie A, La JH, Gebhart GF. Nociceptive and inflammatory mediator upregulation in a mouse model of chronic prostatitis. Pain. 2015;156(8):1537-1544.

52. Yoshioka M, Fukuishi N, Kubo Y, et al. Human cathelicidin CAP18/ LL-37 changes mast cell function toward innate immunity. Biol Pharm Bull. 2008;31(2):212-216.
Journal of Pain Research

\section{Publish your work in this journal}

The Journal of Pain Research is an international, peer reviewed, open access, online journal that welcomes laboratory and clinical findings in the fields of pain research and the prevention and management of pain. Original research, reviews, symposium reports, hypothesis formation and commentaries are all considered for publication.

\section{Dovepress}

The manuscript management system is completely online and includes a very quick and fair peer-review system, which is all easy to use. Visit http://www.dovepress.com/testimonials.php to read real quotes from published authors. 